\title{
Migrating Lump in Abdomen-Ileo-Colo-Colic Intussusception Up to the Rectum with Hypermobile Caecum and Ascending Colon
}

\author{
Kalpesh Patil, Tushar Khachane, Pankaj Bharambe \\ M.I.M.E.R Medical College, Talegaon Dabhade, India \\ Email:dockalpesh@gmail.com, tusharkhachane@yahoo.com,drpankajobharambe@gmail.com
}

How to cite this paper: Patil, K., Khachane, T. and Bharambe, P. (2017) Migrating Lump in Abdomen-Ileo-Colo-Colic Intussusception Up to the Rectum with Hypermobile Caecum and Ascending Colon. Open Journal of Pediatrics, 7, 37-43. https://doi.org/10.4236/ojped.2017.71006

Received: March 2, 2017

Accepted: March 25, 2017

Published: March 28, 2017

Copyright ( 92017 by authors and Scientific Research Publishing Inc. This work is licensed under the Creative Commons Attribution International License (CC BY 4.0). http://creativecommons.org/licenses/by/4.0/

\begin{abstract}
In pediatric age group, Intussusception is the most common cause of acute intestinal obstruction. They present with the classic clinical triad of colicky abdominal pain, vomiting and bloody stools. But clinically very few patients (20\%) present with this classical symptoms. This article highlights an importance of suspecting intussusception by physician and rare presentations of intussusception lump in abdomen in a child with abdominal pain, gastrointestinal symptoms. Here a case reported of 16-year-old male child who presented with migrating lump in abdomen on and off with varied clinical presentation every time in single admission. Patient underwent laparotomy and manual reduction of intussusception was done. It is advisable to have high suspicion of intussusception while dealing with such cases.
\end{abstract}

\section{Keywords}

Ileo-Colo-Colic Intussusception in Children, Hypermobile Cecum and Ascending Colon, Migrating Lump in Abdomen

\section{Introduction}

Intussusception develops when a proximal segment of the gastrointestinal tract telescopes into a distal portion. In United States, Intussusception occurs in approximately 56 children per 100,000 per year of which majority of cases occur before 1 to 2 years of age [1] [2]. It is most commonly encountered with highest incidence between 5 and 9 months of age, and very rarely seen in neonates [2]. Mainly male predominance of 3:2 is observed with ileocecal portion of intestine as frequent site of intussusception. The ideopathic intussusception is most commonly located at hepatic flexure of colon. During intussusception, the invaginated part of proximal intestine and its mesentery encounter compromised ve- 
nous return which leads to edema of mucosa and bleeding from mucosa presenting as Red Currant jelly stools. Once the arterial blood supply of invaginated part of intestine occurs, it leads to necrosis, perforation and sometimes septic shock. Usually early or late presentation of intussusceptions is most likely to have a "lead point" as meckel diverticulum, polyposis of intestines, lymphomas, and Enlarged mesenteric lymph nodes [3]. When cecum, ileo cecal region of intestine and ascending colon along its mesentery fail to fuse to posterior parietal peritoneal wall, it is labelled as Hypermobile cecum and ascending colon, which has been noted in 10 - 20 percent of population [4]. Though this abnormal embryology is noted at high incidence, it rarely presents as a cause of recurrent abdominal pain. Very rarely hypermobile cecum and ascending colon lead to volvulus but once it occurs, it may lead to strangulation of terminal small intestine and gangrene. If the diagnosis of cecal volvulus is delayed, it requires emergency surgical intervention.

\section{Anatomy and Pathophysiology}

Intussusception may vary as per different sites of intestines getting involved such as ileoileal, colocolic, ileo-ileo-colic, or ileocolic. Ileocolic intussusception is the most common site. The most important concerns of intussusception are vascular compromise and necrosis of invaginated intestinal sengment leading to small bowel obstruction, full thickness necrosis of invaginated bowel and perforation with septic shock. An abnormal peristalsis caused by a mass such as lymphoid hyperplasia results in abnormal longitudinal forces on the bowel wall and idiotpathic intussusception, are thought to be responsible for this phenomenon. Suggested predisposing factors for idiopathic intussusception include well-developed lymphoid tissue, a thin intestinal wall, a narrow intestinal lumen, poor fixation of the ileocecal region, viral or bacterial infection, and recent abdominal operation. These factors are thought to result in mesenteric lymphoid or Peyer's patch hyperplasia, abnormal peristalsis, and bowel-wall oedema. As the intestine is drawn into the lumen immediately distal to it, the mesentery is dragged alongside of the proximal bowel wall into the distal lumen resulting in venous congestion.

\section{Clinical Presentation and Diagnosis}

The intussusceptions represent with most classic constellation of signs and symptoms though occurs in only one third of the patients. The infants usually presents with intermittent abdominal pain, vomiting, passage of blood and mucus in stools. During infancy these symptoms are often preceded by an upper respiratory infection. Very rarely similar previous episodes of pain in abdomen, which may or may not be associated with blood in stools, are noted by parents. Such patients with recurrent history are most likely to have a surgical lead point. Pain during intussusception is colicky, severe and intermittent where parents describe typical posture of baby adopting during pain as drawing the legs up to the abdomen and kicking the legs in the air. Intermittently baby may appear 
comfortable with signs of relief. Vomiting initially is non bilious but once intestinal obstruction occurs, vomiting may be bilious along with passage of typical Red currant jelly type stools. Though Diarrhea and lethargy are common presenting symptoms with intussusception, a sole presentation of lethargy may make diagnosis challenging. On clinical evaluation baby may have cyclical periods of lethargy with crying spells, repeating at every 15 to 30 minutes of interval. On per abdominal examination a saussage shaped mass may be palpable in right hypochondrium with emptiness in right lower quadrant of abdomen ("Sign D dance"). Abdominal rigidity and involuntary gurading are present once the intestinal infarction has already to progressed to gangrene and peritonitis. In patients with no classical presentation of intussusception, there may be unfortunate delay in diagnosis and unexplained consequences. Therefore high index of suspicion is essential while dealing with pediatric patients presenting with abdominal pain.

\section{Diagnosis}

Till the advancement of radiological investigations and wide use of ultrasonography as a diagnostic tool, there was high morbidity and mortality associated in cases of intussusception. In fact, only $30 \%-68 \%$ of children with clinical findings suggestive of intussusception are shown to have this condition [5]. Now a days the traditional approach to pediatric intussusception of plain $\mathrm{x}$ ray abdomen and contrast enema study have been changed to ultrasonography of abdomen at many institutions. Ultrasonography of abdomen is carrying sensitivity of $98 \%-100 \%$ and specificity of $88 \%-100 \%$ with high accuracy in diagnosis of intussusception. Contrast enema study could be reserved for therapeutic purposes whenever ultrasonography is unavailable. In cases with confusing symptoms, contrast enhanced tomography (CT) scan of abdomen has helped to diagnose intussusception preoperatively identified with pathognomic appearance as a "sausage shaped mass" and typical "target sign" when the CT beams are perpendicular to longitudinal axis.

\section{Case Report}

Here presenting a case report for academic purpose with informed consent from parents. A 16 year old male child presented to our casualty with history of acute pain in abdomen with two non bilious vomiting episodes since last 8 hours. He gave history of similar episodes of dull aching pain in abdomen in past for 8 to 9 times since childhood but without vomiting. There was no history of other bowel complaints as blood in stools, altered bowel habits or blood in vomitus. On examination, Vitals of the patients were normal. On per abdomen examination there was palpable lump in central quadrant of abdomen around peri-umbilical region which was firm, tender on deep palpation and partially mobile (Figure 1). On Ultrasonography screening of abdomen findings were suggestive of small bowel intussusception with intussuscepted segment length was around 10 $\mathrm{cm}$ with maintained vascularity of bowel (Figure 2). Within 2 hours of admission, 


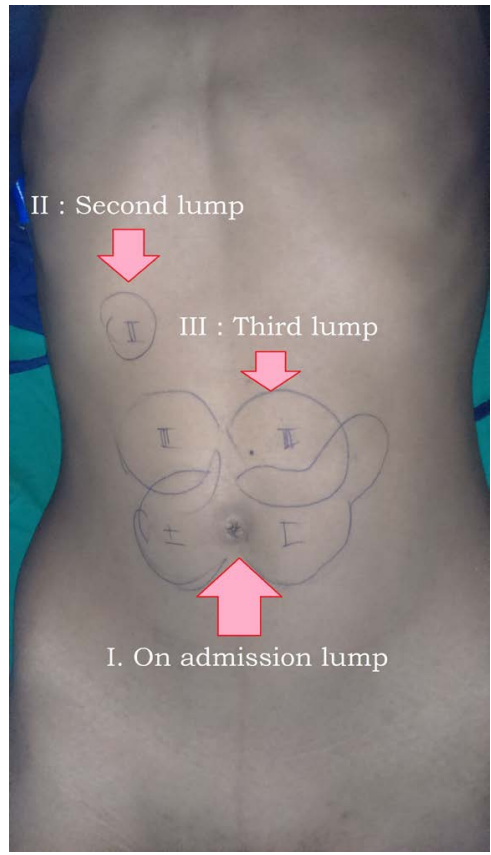

Figure 1. Various locations of migrating abdominal lump in abdomen on clinical examination.

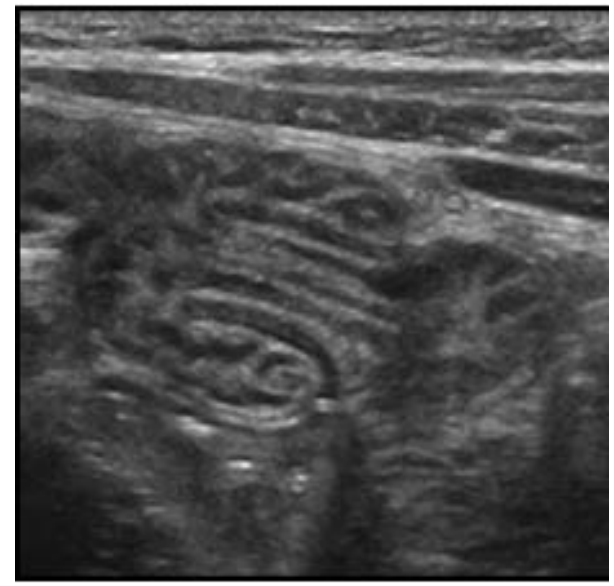

Figure 2. Ultrasonography of abdomen showing small bowel intussusception with typical bowel within bowel loop appearance.

patient became asymptomatic with lump completely disappeared on own. Patient passed normal stools after that so put on oral liquids only and kept under observation. After 12 hours of disappearance of previous lump in abdomen, patient again developed severe pain in abdomen with non bilious vomiting. Clinically on per abdomen examination patient presented with new palpable lump in abdomen in right hypochondriac region which was similar in nature but varying in location (Figure 1). On Ultrasonography screening of abdomen findings were suggestive of Ileo-colic intussusception with good vascularity of bowel. Patient was kept nil by mouth. In 4 hours patient passed normal stools and lump disappeared on clinical examination. Patient was kept nil by mouth over night and kept under observation though bowel sounds were good in quadrants of abdo- 
men. Within next 6 hours of disappearance of second lump in abdomen, patient developed third episode of non radiating pain in abdomen in left iliac fossa without vomiting episodes. On clinical examination, there were two lumps palpable separately in supra umbilical region (Figure 1). On Ultrasonography screening of abdomen was inconclusive as all bowel loops were distended. On Computerised tomography scan (CT Scan) of abdomen findings were bowel within bowel appearance with cecum, ascending colon could not localised (Figure 3). Patient was subjected for emergency exploratory laparotomy with midline incision on abdomen. On exploration there was evidence of ileocolocolic intussusception up to the rectum with long floppy mesentery of invaginating part of ascending colon (Figure 4). Manual reduction of intussusception
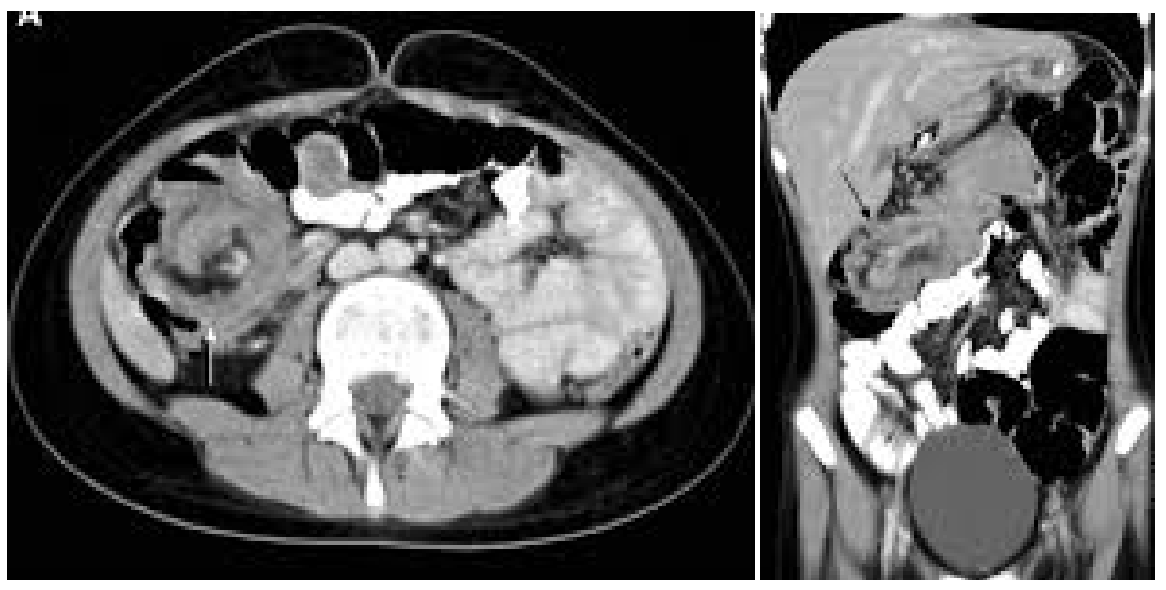

Figure 3. Computerised tomography scan of abdomen showing bowel within bowel appearance with displaced cecum and ascending colon, appendix.

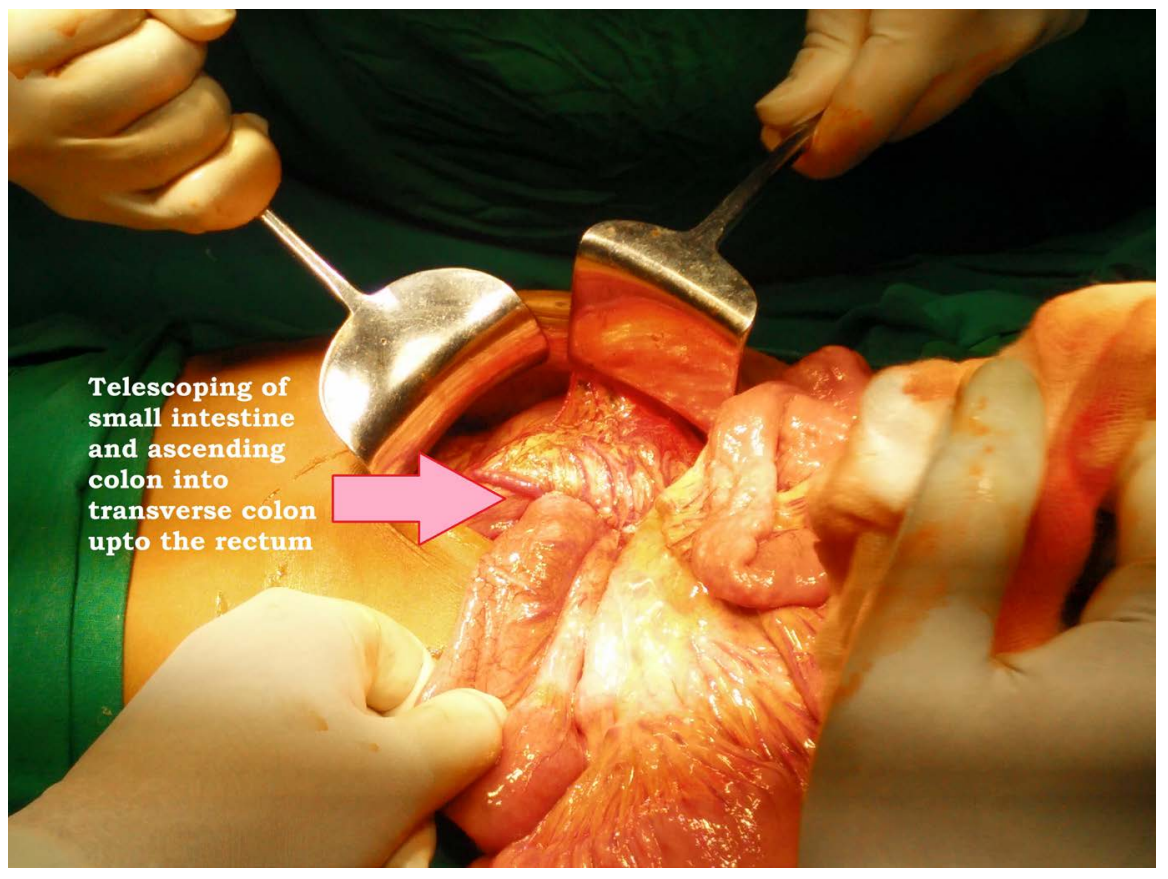

Figure 4. Telescoping of small intestine and ascending colon into transverse colon up to the rectum found during exploratory laparotomy. 
was done successfully without any need of resection anastomosis of bowel as vascularity was maintained well. On Complete reduction, there was evidence of complete hypermobile caecum (Figure 5) and whole of ascending colon with long floppy mesentery of right side colon (Figure 5) along with multiple enlarged lymph nodes (Figure 6). Appendisectomy was done and cecopexy and fixation of ascending colon to retroperitoneal folds done. Post operative stay of patient was uneventful. Patient is asymptomatic till date over last 1 year of follow up.

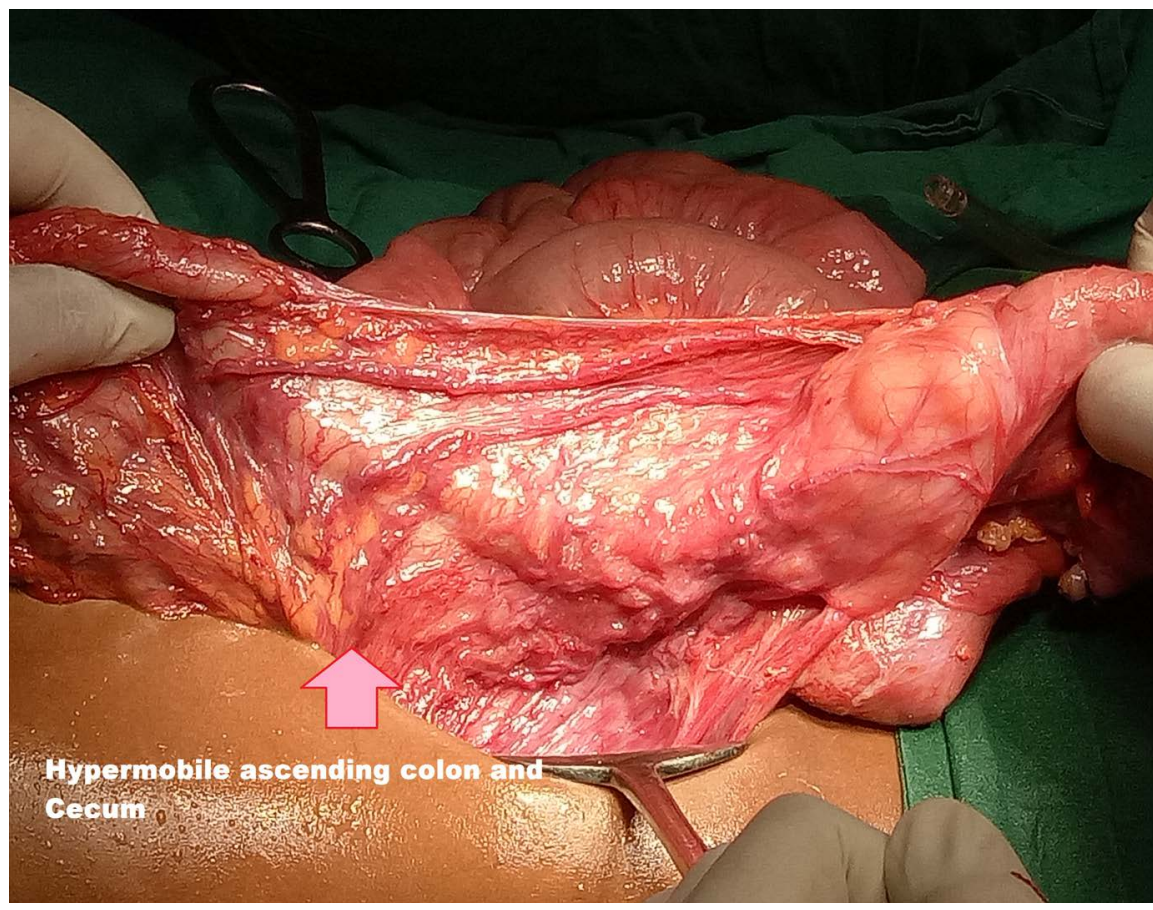

Figure 5. Hyper mobile whole of ascending colon with floppy retroperitoneal mesenteric attachment.

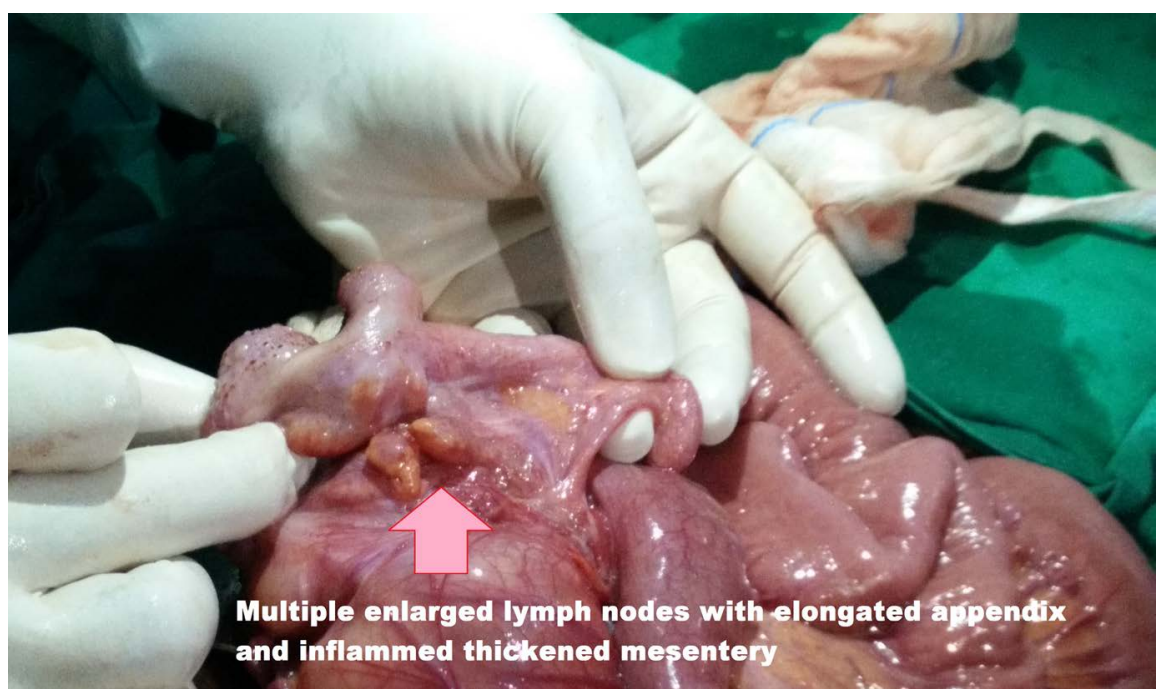

Figure 6. Multiple enlarged lymph nodes near ileo cecal junction with thickened mesentery. 


\section{Discussion}

Hyper mobile cecum may present with intermittent bouts of abdominal pain till cecal obstruction gets spontaneously resolved falling back to its normal anatomical position. Cecopexy, using lateral peritoneal flap, which was first described by Dixon and Meyers in 1948 [6], best achieves fixation of the mobile cecum. It is said to be the surgery of choice for the mobile cecum which is an easy and quick procedure also reduces chances of recurrence of intussusception. In recent times laparoscopic cecopexy is gaining popularity and is fast becoming the treatment of choice [7]. As discussed in this case report, intussusception can present with unusual way and may be really confusing to diagnose clinically and to decide plan of action preoperatively. So as a Pediatrician and Pediatric surgeon, we must keep in mind about such unusual presentations of intussusception to gain high clinical acumen.

\section{Conclusion}

Intussusception is less commonly encountered in the adolescent age group, and this, along with the vague clinical features, makes diagnosis difficult. Ultrasonography and computed tomography scan of abdomen have very effective role in diagnosis of intussusception. In adolescent age group and in adults, intussusception is usually associated with surgical lead point and should be tackled on time.

\section{References}

[1] Applegate, K.E. (2005) Clinically Suspected Intussusception in Children: EvidenceBased Review and Self-Assesment Module. American Journal of Roentgenology, 185, S213. https://doi.org/10.2214/ajr.185.3_supplement.0185s175

[2] Sorantin, E. and Lindbichler, F. (2004) Management of Intussussception. European Radiology, 14, L146-L154. https://doi.org/10.1007/s00330-003-2033-2

[3] Behrman, R.E., Kliegman, R.M. and Jenson, HB. (2007) Nelson Textbook of Pediatrics. Intussusception, 1569-1570.

[4] Rogers, R.L. and Harford, F.J. (1984) Mobile Caecum Syndrome. Diseases of the Colon \& Rectum, 27, 399-402. https://doi.org/10.1007/BF02553011

[5] Verschelden, P., Filiatrault, D., Garel, L., et al. (1992) Intussusception in Children: Reliability of US in Diagnosis-A Prospective Study. Radiology, 184, 741-744. https://doi.org/10.1148/radiology.184.3.1509059

[6] Dixon, C.F. and Meyer, A.C. (1948) Volvulus of the Caecum. Surgical Clinics of North America, 28, 953-963. https://doi.org/10.1016/S0039-6109(16)32484-7

[7] Tsushimi, T., Kurazumi, H., Takemoto, Y., Oka, K., Inokuchi, T., Seyama, A., et al. (2008) Laparoscopic Caecopexy for Mobile Caecum Syndrome Manifesting as Caecal Volvulus: Report of a Case. Surgery Today, 38, 359-362. https://doi.org/10.1007/s00595-007-3620-7 
Submit or recommend next manuscript to SCIRP and we will provide best service for you:

Accepting pre-submission inquiries through Email, Facebook, LinkedIn, Twitter, etc. A wide selection of journals (inclusive of 9 subjects, more than 200 journals)

Providing 24-hour high-quality service

User-friendly online submission system

Fair and swift peer-review system

Efficient typesetting and proofreading procedure

Display of the result of downloads and visits, as well as the number of cited articles Maximum dissemination of your research work

Submit your manuscript at: http://papersubmission.scirp.org/

Or contact ojped@scirp.org 